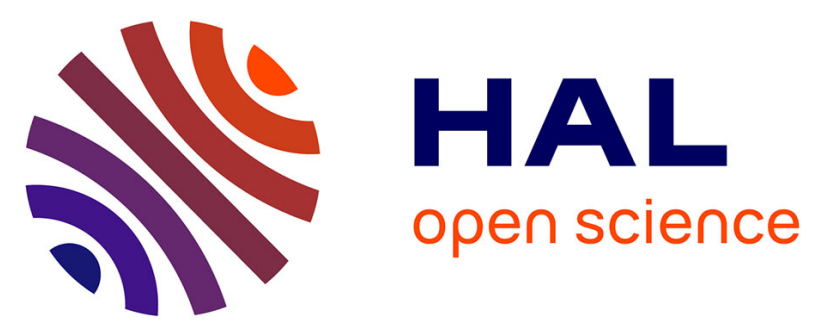

\title{
Development of a weighted scale to assess the quality of cost-effectiveness studies and an application to the economic evaluations of tetravalent HPV vaccine
}

Giuseppe La Torre, Nicola Nicolotti, Chiara de Waure, Walter Ricciardi

\section{To cite this version:}

Giuseppe La Torre, Nicola Nicolotti, Chiara de Waure, Walter Ricciardi. Development of a weighted scale to assess the quality of cost-effectiveness studies and an application to the economic evaluations of tetravalent HPV vaccine. Journal of Public Health, 2010, 19 (2), pp.103-111. 10.1007/s10389-0100377-z . hal-00589723

\section{HAL Id: hal-00589723 \\ https://hal.science/hal-00589723}

Submitted on 1 May 2011

HAL is a multi-disciplinary open access archive for the deposit and dissemination of scientific research documents, whether they are published or not. The documents may come from teaching and research institutions in France or abroad, or from public or private research centers.
L'archive ouverte pluridisciplinaire HAL, est destinée au dépôt et à la diffusion de documents scientifiques de niveau recherche, publiés ou non, émanant des établissements d'enseignement et de recherche français ou étrangers, des laboratoires publics ou privés. 
Development of a weighted scale to assess the quality of cost-effectiveness studies and an application to the economic evaluations of HPV tetravalent vaccine

Authors: La Torre Giuseppe ${ }^{1-2}$, Nicolotti Nicola ${ }^{1}$, de Waure Chiara ${ }^{1}$, Ricciardi Walter ${ }^{1}$

Affiliations: 1: Research Center of Health Engineering and Health Technology Assessment, Institute of Hygiene, Catholic University of the Sacred Heart; L.go F. Vito 1, 00168 Rome; 2: Department of Experimental Medicine, Sapienza University of Rome, Viale Regina Elena 324, 00185 Rome.

Running title: Assessing quality of economic analysis

\section{Email of authors:}

Prof. La Torre Giuseppe: giuseppe.latorre@uniroma1.it

Dr. Nicolotti Nicola: nicola.nicolotti@gmail.com

Dr. de Waure Chiara: chiara.dewaure@rm.unicatt.it

Prof. Ricciardi Walter: wricciardi@rm.unicatt.it

\section{Address for correspondence}

Chiara de Waure, MD, MPH

Institute of Hygiene,

Catholic University of the Sacred Heart

L.go F. Vito 1, 00168 Rome

Phone: +3906 35001525; Fax: +3906 35001522

E-mail: chiara.dewaure@rm.unicatt.it, chiaradw@alice.it 


\section{ABSTRACT}

Aim: Interest in quality of economic analyses is increasing in the field of decision making. The Drummond's checklist is a useful tool. This study aimed to use a weighted version of Drummond's checklist together with a Consensus of experts to derive a new scoring system to improve the evaluation of economic analyses of HPV tetravalent vaccine as a case study.

Methods: Drummond's checklist is composed of 35 items divided into 3 sections: study design, data collection and analysis and interpretation of results. To weight the items, a group of experts was asked to attribute a score according to their importance. A bibliographic search of economic evaluations of HPV tetravalent vaccine was performed. Two researchers assessed the quality of selected studies according to the original and weighted checklist.

Results: The weighted scores assigned by the Consensus to study design, data collection and analysis and interpretation of results were 26,45 and 48 respectively. Thirteen papers were included in the review of economic evaluations of HPV tetravalent vaccine. According to the weighted Drummond's checklist, their median quality score was 74 with a maximum of 119 . The highest score was reached in study design section.

Conclusion: According to the weighted Drummond's checklist, studies were judged of medium quality. The main pitfalls were found in issues assigned the highest scores by the Consensus, underlying the utility to weight available checklists to improve the estimate of the quality of economic analyses. The weighted checklist could be thus proposed as a scoring tool to assess the quality.

Keywords [MeSH]: Costs and Cost Analysis, Papillomavirus Vaccines, quality, Health Technology Assessment 


\section{BACKGROUND}

The introduction of economic evaluation in health started at the end of the 1970s (Weinstein and Stason 1977). Since that period, there has been a spreading and growing interest in health economic analysis and, at the same time, the emerging need for assuring their methodological and reporting quality (Elixhauser 1993; Drummond 1996). As an example, Elixhauser et al. (1993; 1998) estimated that the number of economic analyses published in literature increased from 1803 in $1979-90$ to 2222 in 1991-96.

Economic analyses have been increasingly used by decision-makers in the field of public health in order to allocate limited resources (Beutels 2007). The introduction of a new technology causes a great mobilisation of resources and, for these reasons, decisions should be supported by high quality evidence. In several European and extra-European countries, decisions about reimbursement and price of new drugs are taken considering not only safety, efficacy and effectiveness, but also costeffectiveness. In some countries, such as Australia, Canada, Sweden, Netherlands, Ireland, Norway, Finland, Belgium, Estonia, Latvia and United Kingdom, this economic analysis is compulsory in order to determine the price and reimbursement of new and innovative drugs (Russo 2008). In other countries, such as Italy, France, Germany and Greece, the inclusion of pharmacoeconomic analysis into price or reimbursement requests is not mandatory (Russo 2008).

Therefore, the need to control and evaluate the quality of reporting and methods used in pharmaeconomic analyses is clearly a fundamental issue for public health decision-makers (Jefferson 2002).

Drummond et al. (1996; 1997) published the guidelines for the evaluation of the quality of economic analyses both for authors and reviewers on the basis of a qualitative judgement only; the checklist has become one of the most commonly employed in the quality assessment of economic evaluations. Moreover, it has been affirmed that the Drummond's checklist is a feasible tool to collect baseline information on the quality of studies, irrespectively of the journals which published them (Gerard 2000). Several reports of quality assessment of economic analyses have been 
published (Neumann 2000; Siegel 1996; Gerard 1999; Petrou S 2000). Also, the evaluation of the quality of studies is a well-known step in systematic reviews and meta-analyses (Higgins and Green 2008; Centre for Reviews and Dissemination 2009) which are becoming increasingly important to support decision-making. In this context, the need for developing and implementing the use of quality assessment tools in the field of economic evaluation is a priority to enable decision-makers to understand the reliability and robustness of data (La Torre 2006). Checklists are described as a tool for assessing the quality of studies, even though scoring systems are not generally recommended. In particular, for economic analysis, available scoring systems were judged to be not completely reliable and valid (Thurston 2008). Several experts advocate the use of weighted items of checklists for the evaluation of economic analyses (Ungar and Santos 2003; Gonzalez Perez 2002). Moreover, currently available scoring systems for assessing the quality of economic analysis are, in same cases, not based on a well-known and commonly shared checklist but on key elements drawn from different checklists (Chiou 2003; Wallace 2002; Ungar and Santos 2003); others were developed which gave a full score to items for which an explicit answer was retrievable in the text and half score in the case of a not clear answer in the text (Gonzalez Perez 2002). All these systems were judged to be useful for researchers and policy-makers to evaluate the quality of studies, even though they have limits. We believe that further effort could be made to assign each item more or less weight according to its importance, as noted by Chiu et al. (2003). With this aim, we chose the most common and well-known checklist nowadays available to try to develop a new scoring system for decision-makers to evaluate the quality of studies and perform stratified and sensitivity analyses in systematic reviews. The novelty of the work is the choice of the most commonly used checklist, the involvement of experts not necessarily belonging to economists and the attempt to develop a user-friendly weighted scoring system.

The old and new developed checklists were then used to assess the quality of economic analyses on tetravalent Human Papillomavirus (HPV) vaccine (against genotypes 6, 11, 16 and 18). This work derives from a Health Technology Assessment (HTA) project about the tetravalent HPV vaccine 
(La Torre 2009). HTA is a multidisciplinary approach to evaluate the introduction or the implementation of technology that takes into account epidemiological, clinical, technical, economic, organisational, social, legal, ethical topics; HPV vaccine was the first which aimed to prevent an oncological disease. In carrying out HTA on tetravalent HPV vaccine, published economic analyses on tetravalent vaccine were assessed in order to evaluate their quality and to summarise data about its cost-effectiveness.

The specific aims of this work were: 1) to attribute a weight to the items of the original Drummond's checklist which was employed to assess the quality of studies; 2) to apply the original and the weighted Drummond's checklist to the economic analyses of tetravalent HPV vaccine as a case study of the application of the weighted checklist.

\section{METHODS}

\section{Checklist weighting process}

The British Medical Journal (BMJ) referees' checklist, proposed by Drummond et al. (1996) and specific for economic evaluation, was chosen as the quality assessment tool for the study. It is composed of 35 items divided into 3 sections: study design (7 items), data collection (14 items) and analysis and interpretation of results (14 items). Each item could be completely satisfied (Yes) or not (No) or not clearly reported (Not clear) or not applicable (Not appropriate).

To accomplish for our first objective, that to attribute a weight to each item of the checklist, an opportunistic sample of experts (Consensus) in health economics, epidemiology and public health was selected among key professionals involved in economic evaluation in Italy. The opportunistic sample of experts was asked, by e-mail, to attribute, according to their personal knowledge and experience, a possible score from 1 to 4 to each item of the original Dummond's checklist:

- Score 1: Less important item;

- Score 2: Important item; 
- Score 3: Very important item;

- Score 4: Essential item.

Whenever an answer to the first invitation was not obtained, a maximum of two reminders by email were sent. The median values of weights assigned by the Consensus to each item were considered to compute the highest global and section scores.

The Kruskal-Wallis test was applied to assess any difference in weights assigned to each item by the three groups of experts involved in weighting. The result of Kruskal-Wallis was used to make the decision to combine data from all the experts or to perform a separate analysis according to the experts' backgrounds.

The statistical significant level was set at $\mathrm{p}=0.05$. The statistical analysis was performed using SPSS 12.0 for Windows.

\section{Identification of relevant studies and quality assessment}

A bibliographic search of articles written in English on the economic evaluation of HPV tetravalent vaccine was performed (until $1^{\text {st }}$ March 2009) using Pubmed. The search was carried out on Pubmed using the following algorithm: ("Quadrivalent"[All Fields] OR "tetravalent"[All Fields]) AND ("Papillomavirus Vaccines"[All Fields] OR "Papillomavirus Vaccines"[Mesh] OR "HPV vaccine"[All Fields]) AND ("Costs and Cost Analysis"[All Fields] OR "Costs and Cost Analysis"[Mesh] OR “Cost-Benefit Analysis"[Mesh]). In order to identify other possible studies of interest, electronic research was supplemented by manual examination of the reference lists of articles found by the Pubmed search, in order to find out all the available full and partial economic evaluations of HPV tetravalent vaccine. Economic analyses published only on national reports of technology evaluation were not included in our analysis.

In the selection process, abstracts were first read independently by two researchers (CdW and NN) to identify potentially eligible papers whose full text was retrieved and assessed in order to decide on the final inclusion. 
For each selected study, two researchers (CdW and $\mathrm{NN}$ ) assessed independently the quality according to the original Drummond's checklist. Discrepancies between the two investigators were solved by oral discussion and consensus with a senior investigator (GLT). After this first evaluation, each item was assigned with the median weight attributed by the Consensus, if satisfied at the application of the original Drummond's checklist. Finally the global score was computed summing up weights of each item. To compare between studies, global scores were referred, in percentage, to the highest score achievable with the weighted Drummond's checklist.

\section{RESULTS}

\section{Checklist weighting process}

The Consensus of experts selected for the weighting was composed of 25 people; 17 of them agreed to partecipate (6 health economists, 5 epidemiologists and 6 public health experts). Non-responders were 2 epidemiologists, 2 public health experts and 4 health economists; 3 refused to join the Consensus while the others did not answer the mail invitations. The Drummond's checklist with median weights assigned to each item is shown in table 1 . In the table, median scores given by each group of experts are also reported alongside with p-values resulted by the Kruskal-Wallis test.

Please insert table 1 here

For each section of items the maximum achievable score was as follows:

1. Study design (7 items):

Maximum global score $=26$;

2. Data collection (14 items):

Maximum global score $=45$;

3. Analysis and interpretation of results (14 items):

a. Maximum global score $=48$; 
Little differences were observed between weights assigned by the three expert groups: none of the 35 items produced a statistically significant difference.

The global achievable highest score (table 1) was thus 119.

\section{Identification of relevant studies}

From the literature search (35) and bibliographic list reviewed (45), 80 potential eligible studies were retrieved. After title and abstracts reading, 21 passed to the full-text review. Thirteen out of 21 papers were finally included in the analysis (Insinga 2007; Insinga 2008; Chesson 2008; Elbasha 2007; Brisson 2007; Bergeron 2008; Ginsberg 2007; Boot 2007; Dasbach 2008; Szucs 2008; Kulasingam 2008; Jit 2008; Mennini 2005). All the articles which dealt with economic analysis of bivalent vaccine (against genotypes 16 and 18) were excluded as well as papers in non English language. Details about excluded articles are reported in figure 1. Twelve out of 13 papers were cost-effectiveness analyses while one (Insinga 2008) was a cost of illness analysis based on the FUTURE study, a trial on HPV tetravalent vaccine.

\section{Please insert figure 1 here}

\section{Quality assessment}

Considering the original Drummond's checklist, all the studies clearly defined the research objective and question (item 1) and sources of efficacy data (item 8), and reported appropriate conclusions (item 34) giving a satisfactory answer to the research question (item 33). In most studies (about 8-12 out of 13) something was stated about the economic importance of the research (item 2), viewpoint of analysis was clarified and justified (item 3), comparators and rationale of their choice were clearly described (items 4 and 5). In the mean time, economic analysis type (item 6), outcomes (item 11), methods to evaluate health status and benefits (item 12), money currency (item 18), model details (item 20), time horizon of analysis (item 22) and discount rate (item 23) were described. Moreover most studies stated that a sensitivity analysis was performed (item 27) 
and described ranges of parameter variation (item 29). Most studies compared relevant alternatives in the model (item 30) and reported incremental analysis (item 31); the studies' limits were moreover discussed in most of works (item 35).

The flaws identified in the studies were: the choice of the model was not justified (item 7), details of efficacy sources and of patients on whom data were retrieved were missing (items 9 and 13); resources and costs were not reported separately (16), methods for their computation were not described (item 17) and details of adjustment for inflation or currency conversion (item 19) were not given. Moreover the choice of model, parameters, discount rate and parameters to vary was not justified (items 21, 24, 28). Studies were lacking details of statistical analysis (item 26) and results were often reported only in an aggregate way (item 32). For details about each single item see table 2.

\section{Please insert table 2 here}

According to our weighted Drummond's checklist, the median quality score of selected studies resulted 74 (Min: 46; Max: 80). The highest score was reached in the study design section; median score of this part was 19 (Min: 12; Max: 26) and only one study (Brisson 2007) attained the maximum possible score. Good results were achieved also in the analysis and interpretation of results section: median score was 30 (Min: 21; Max: 42).

The lowest median score was observed in the data collection (Median: 22; Min: 10; Max: 31). Table 3 shows quality assessment results. It can be noted that almost all studies received a quality score over the $50 \%$ of the highest possible, 119 , but none reached $70 \%$ of it.

Please insert table 3 here 


\section{DISCUSSION}

The present study deals with Drummond's checklist which is already widely used by authors and reviewers to assess the completeness of economic analysis reporting. Different attempts to assess the quality of reporting have been carried out by different authors.

Neumann et al. (2000) published a work about the assessment of 228 cost-utility analyses over the period 1976-97; they employed a form, developed on the basis of the "checklist" for reporting reference-case cost-utility analyses recommended by the Panel on Cost-Effectiveness in Health and Medicine (Siegel 1996), other published guidelines and by recommendations and discussions with experts in the field. Collected data ranged from disclosure of funding sources, reporting of the framing of analysis, reporting of costs, preference weights, results, and description of key elements in the discussion section. The results revealed that the weakest parts were the definition of study perspective, the provision of a diagram of the model or event pathway, the reporting of the discount rate for both costs and quality adjusted life years, the definition of the year in which monetary units were valued, the appropriate reporting of incremental cost-effectiveness ratios and the discussion of ethical implications.

Further experiences on evaluation of economic analyses were carried out in the 1990s. Gerard et al. (1999) showed incongruent perspectives and serious deficiencies in the estimation of costs, interpretation of results and the use of patients for eliciting utility weights, whereas Petrou et al. (2000) analysed 41 works on antenatal screenings accounting for methodological topics on the basis of Drummond's guideline. The weakest areas were: failure to provide detailed and disaggregated information on reported costs, failure to discount future care costs and the poor use of sensitivity analysis, often applied only to clinical or epidemiological parameters.

Our study adds the weighting of each evaluation item to previous analyses. The assessing of the quality of economic analyses aids informed reading of the current literature and improves homogeneity and reliability of decision-making process. That is why we chose to use a newly developed and widely used checklist to weight the importance of each item using the opinions of a 
group of well-known experts in epidemiology, public health and economics who were involved in health economic analyses from different viewpoints and thus representative of all the perspectives in the evaluation of economic analysis. The development of the weighting system was the main goal of our work so that assessment of the quality of economic analyses could be more thorough. It must be underlined that other attempts to weight Drummond's checklist have been reported: GonzalezPerez (2002) demonstrated that the development of a weighting system improves discrimination of the quality of studies and of their importance, robustness and correctness.

The present work of weighting found that the most important aspects to be considered in economic analyses are: for study design, the definition/justification of the research question, viewpoint of analysis, alternatives and form of economic evaluation; for data collection, the description of outcomes, model and its parameters, sources of effectiveness data and methods to evaluate health benefits and costs; for interpretation of results, the identification of the time horizon, discount rate and sensitivity analysis and justification of conclusions.

Most of these elements were identified as main flaws of economic analyses by Drummond (2005) himself; he also underlined the potential problems coming from indirect comparisons, inappropriate extrapolation beyond the period observed in clinical studies, the excessive use of assumptions rather than data, and the selective reporting of findings.

The well recognised importance of such elements could justify, in our opinion, the development of a scoring system able to assign different value to single items of already available checklists.

Also it is very interesting to observe that methodological lacks and flaws are not only present in published studies but also in economic evaluations of dossiers sent to institutional bodies for decisions on drugs reimbursement or price. This was verified both in Italy and in an international setting (Russo 2008; Hill 2000). For these reasons, in our opinion, it is important to underline that the introduction of a new technology, such as a vaccine, should be based not only on economic evaluation but on a multidisciplinary assessment, such as the Health Technology Assessment which also includes an economic evaluation (La Torre 2007). 
Our second aim was to apply the Drummond's tool, both as checklist and as quality score system, to the economic evaluations of HPV tetravalent vaccine in the context of an HTA project. HPV vaccine is a relatively new topic in the international scenario and in Italy has been introduced, free of charge, for twelve years old girls; the increasing interest has led during the last two years to several publications concerning health economic aspects. It is presumable that the growing interest in economic assessment has been also driven by the need for evidence to support decision-makers. Our review yielded 13 papers on the economic evaluation of HPV tetravalent vaccine: 4 of them were American (2 in USA, 1 in Canada, 1 in Mexico) whereas 7 were European and 1 Israeli. One study was the economic evaluation of the FUTURE II study, a multicentric randomised clinical trial on tetravalent vaccine.

After assessing the articles for quality, economic evaluations of HPV tetravalent vaccine were found to be of medium quality. The most important quality problems were in "data collection" and "analysis and interpretation of results". For data collection, lack of quality was mainly due to problems about reporting of efficacy, utility, resources and costs sources. On the other hand, analysis and interpretation of results were affected by lack of statistical details, justification of discount rates and sensitivity analysis. It is interesting to observe that these items were assigned the highest weights by the Consensus: this means that the quality evaluation performed with the weighted Drummond's checklist led to relative worse results than the application of the original unweighted checklist.

Our work does have limitations. First, one of the most important weaknesses is that the weighting of Drummond's checklist items was performed only by a narrow group of experts who were all Italians. This means that our work is not conclusive and further experience of weight attribution nationally and internationally would be desirable; the validation of the system of weights assigned by the Consensus of experts should be monitored in order to assess its reliability. Moreover, the scoring system used here cannot reflect the total quality of papers because Drummond's checklist is focused on reporting of results and not on methods used to carry out the analysis. In any case, it 
may be difficult to standardise some aspects of economic evaluations such as the kind of model to use or the discount rate to apply. For this review of HPV tetravalent vaccine economic analyses, the main weakness is the possible selection bias due to the search strategy; in fact, a lot of studies have been carried out worldwide to investigate the economic implications of this vaccine, and thus it is possible that several studies were not selected. The limited search strategy excluded economic analyses reported only on HTA dossiers and not published in peer review journals available on Pubmed. Moreover, studies carried out in Asia or in Africa, as well as in other countries but not written in English, could not be included in the analysis. Alongside selection bias, sponsor bias and publication bias cannot be excluded.

\section{CONCLUSION}

Drummond's checklist could be proposed as a standard reference to evaluate economic analyses and the system of weights could lead to better quality assessment. This could improve a critical evaluation of literature.

\section{ACKNOWLEDGEMENTS}

This work is a part of a Health Technology Assessment project on tetravalent HPV vaccine funded by Sanofi Pasteur MSD. Moreover, we would like to thank Prof. John Osborn for the linguistic revision of the manuscript.

\section{CONFLICT OF INTEREST STATEMENT}

Authors declare to have no conflict of interest. 
Table 1: Drummond's checklist weighting - median score for each item by different experts

\begin{tabular}{|c|c|c|c|c|c|c|c|}
\hline$/$ & \multicolumn{2}{|r|}{$\underline{\text { ITEM }}$} & $\begin{array}{l}\overrightarrow{\vec{E}} \\
\overrightarrow{\bar{E}} \\
\vec{E} \\
\vec{E}\end{array}$ & 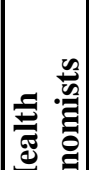 & 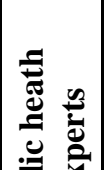 & 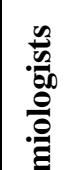 & $\frac{*}{\stackrel{*}{\sigma}}$ \\
\hline \multirow{8}{*}{ 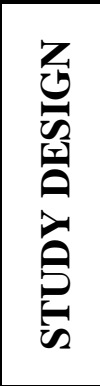 } & 1 & The research question is stated & 4 & 4 & 4 & 4 & 0.99 \\
\hline & 2 & The economic importance of the research question is stated & 3 & 3 & 3.5 & 3 & 0.56 \\
\hline & 3 & The viewpoints of the analysis are clearly stated and justified & 4 & 4 & 4 & 3 & 0.09 \\
\hline & 4 & The rationale for choosing the alternatives programs or interventions compared is stated & 4 & 4 & 4 & 3 & 0.71 \\
\hline & 5 & The alternatives being compared are clearly described & 4 & 4 & 3.5 & 3 & 0.10 \\
\hline & 6 & The form of economic evaluation used is stated & 4 & 3.5 & 4 & 4 & 0.46 \\
\hline & 7 & The choice of form of economic evaluation is justified in relation to the question addressed & 3 & 3 & 3 & 3 & 0.59 \\
\hline & & Total & 26 & 25.5 & 26 & 23 & \\
\hline \multirow{15}{*}{ 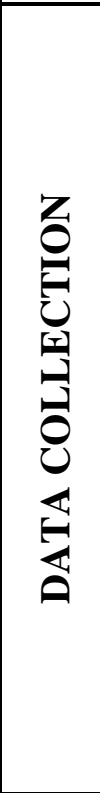 } & 8 & The sources of effectiveness estimates used are stated & 4 & 4 & 4 & 4 & 0.40 \\
\hline & 9 & $\begin{array}{l}\text { The details of the design and results of effectiveness study are given (if based on a single } \\
\text { study) }\end{array}$ & 3 & 3.5 & 3 & 4 & 0.55 \\
\hline & 10 & $\begin{array}{l}\text { Details of the method of synthesis or meta-analysis of estimates are given (if based on an } \\
\text { overview of a number of effectiveness study) }\end{array}$ & 3 & 3.5 & 3 & 4 & 0.50 \\
\hline & 11 & The primary outcome measures for the economic evaluation are clearly stated & 4 & 4 & 4 & 4 & 0.79 \\
\hline & 12 & Methods to value health states and other benefits are stated & 4 & 4 & 3.5 & 4 & 0.41 \\
\hline & 13 & Details of the subjects from whom evaluations were obtained are given & 3 & 2.5 & 3 & 3 & 0.42 \\
\hline & 14 & Productivity changes (if included) are reported separately & 2 & 2.5 & 2.5 & 2 & 0.33 \\
\hline & 15 & The relevance of productivity changes to the study question is discussed & 2 & 2 & 3 & 2 & 0.57 \\
\hline & 16 & Quantities of resources are reported separately from their unit costs & 3 & 3 & 3 & 3 & 0.73 \\
\hline & 17 & Methods for the estimation of quantities and unit costs are described & 4 & 4 & 3 & 4 & 0.40 \\
\hline & 18 & Currency and price data are recorded & 3 & 4 & 3 & 3 & 0.15 \\
\hline & 19 & Details of currency of price adjustment for inflation or currency conversion are given & 3 & 2.5 & 2.5 & 3 & 0.82 \\
\hline & 20 & Details of any model used are given & 3 & 3.5 & 3 & 4 & 0.07 \\
\hline & 21 & The choice of model used and the key parameters on which it is based are justified & 4 & 3.5 & 3 & 4 & 0.08 \\
\hline & & Total & 45 & 46.5 & 43.5 & 48 & \\
\hline \multirow{15}{*}{ 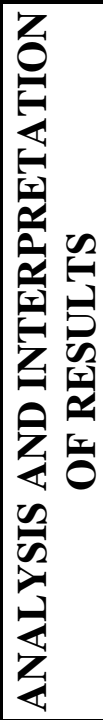 } & 22 & Time horizon of costs and benefits is stated & 4 & 4 & 4 & 4 & 0.95 \\
\hline & 23 & The discount rate is stated & 4 & 4 & 3 & 4 & 0.78 \\
\hline & 24 & The choice of rates are justified & 3 & 3.5 & 3 & 3 & 0.66 \\
\hline & 25 & An explanation is given if costs or benefits are not discounted & 3 & 2.5 & 3 & 3 & 0.46 \\
\hline & 26 & Details of statistical tests and confidence intervals are given for stochastic data & 3 & 3 & 3 & 4 & 0.78 \\
\hline & 27 & The approach to sensitivity analysis is given & 4 & 3.5 & 4 & 3 & 0.42 \\
\hline & 28 & The choice of variables for sensitivity analysis is justified & 3 & 3 & 3 & 3 & 0.62 \\
\hline & 29 & The ranges over which the variables are varied are stated & 3 & 3.5 & 3 & 3 & 0.22 \\
\hline & 30 & Relevant alternatives are compared & 3 & 4 & 3 & 3 & 0.06 \\
\hline & 31 & Incremental analysis is reported & 3 & 4 & 3 & 2 & 0.09 \\
\hline & 32 & Major outcomes are presented in a disaggregated as well as aggregated form & 3 & 2.5 & 3.5 & 3 & 0.61 \\
\hline & 33 & The answer to the study question is given & 4 & 4 & 4 & 4 & 0.97 \\
\hline & 34 & Conclusions follow from the data reported & 4 & 4 & 4 & 4 & 0.14 \\
\hline & 35 & Conclusions are accompanied by the appropriate caveats & 4 & 3.5 & 3.5 & 4 & 0.17 \\
\hline & & Total & 48 & 49 & 47 & 47 & \\
\hline Kru & & Total & 119 & 121 & 116.5 & 118 & \\
\hline
\end{tabular}

Table 2: Quality assessment results, according to Drummond's checklist 


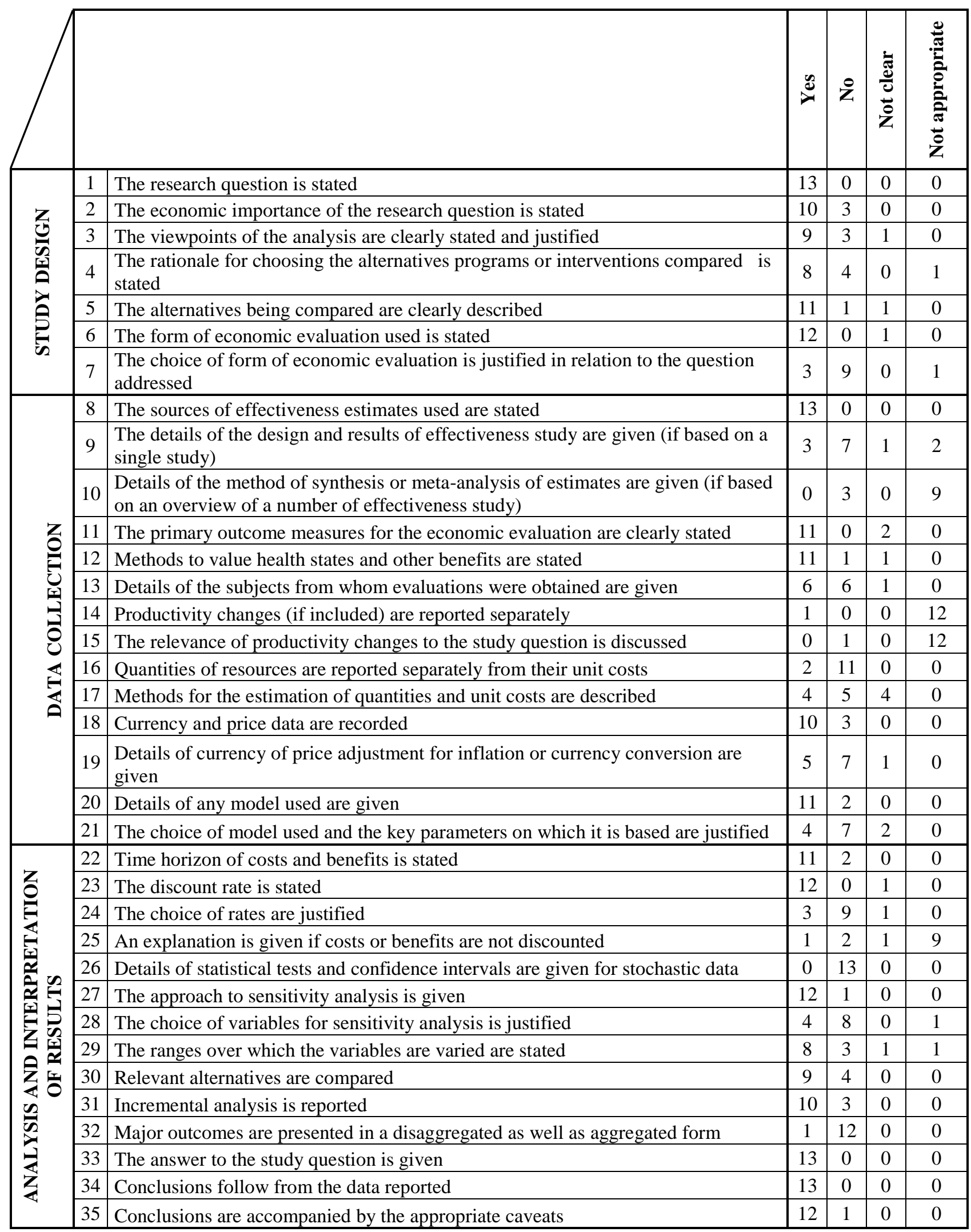


Table 3. Results of quality assessment with weighted Drummond's checklist

\begin{tabular}{|c|c|c|c|c|c|}
\hline & $\begin{array}{l}\text { STUDY } \\
\text { DESIGN }\end{array}$ & $\begin{array}{c}\text { DATA } \\
\text { COLLECTION }\end{array}$ & $\begin{array}{c}\text { ANALYSIS AND } \\
\text { INTERPRETATION OF RESULTS }\end{array}$ & $\begin{array}{l}\text { FINAL } \\
\text { SCORE }\end{array}$ & $\begin{array}{l}\text { TOTAL RELATIVE } \\
\text { SCORE^ }^{\wedge} \\
\end{array}$ \\
\hline Bergeron 2008 & 15 & 21 & 42 & 78 & 65.5 \\
\hline Boot 2007 & 15 & 10 & 21 & 46 & 38.7 \\
\hline Brisson 2007 & 26 & 17 & 26 & 69 & $\mathbf{5 8 . 0}$ \\
\hline Chesson 2008 & 22 & 25 & 29 & 76 & 63.9 \\
\hline Dasbach 2008 & 19 & 31 & 30 & 80 & 67.2 \\
\hline Elbasha 2007 & 19 & 14 & 33 & 66 & 55.5 \\
\hline Ginsberg 2007 & 23 & 24 & 33 & 80 & 67.2 \\
\hline Insinga 2007 & 23 & 21 & 30 & 74 & 62.2 \\
\hline Insinga 2008 & 12 & 28 & 30 & 70 & 58.8 \\
\hline Jit 2008 & 19 & 21 & 30 & 70 & 58.8 \\
\hline Kulasingam 2008 & 16 & 26 & 30 & 72 & 60.5 \\
\hline Mennini 2009 & 23 & 22 & 33 & 78 & 65.5 \\
\hline Szucs 2008 & 19 & 25 & 33 & 77 & 64.7 \\
\hline
\end{tabular}

$\wedge$ The total relative score was computed dividing the final score by the maximum achievable score of 119. 


\section{REFERENCES}

Bergeron C, Largeron N, McAllister R, Mathevet P, Remy V (2008) Cost-effectiveness analysis of the introduction of a quadrivalent human papillomavirus vaccine in France. Int $\mathbf{J}$ Technol Assess Health Care 24:10-9

Beutels P, Thiry N, Van Damme P (2007) Convincing or confusing? Economic evaluations of childhood pneumococcal conjugate vaccination--a review (2002-2006). Vaccine 25:1355-67

Boot HJ, Wallenburg I, de Melker HE et al (2007) Assessing the introduction of universal human papillomavirus vaccination for preadolescent girls in The Netherlands. Vaccine 25:6245-56

Brisson M, Van de Velde N, De Wals P, Boily MC (2007) The potential cost-effectiveness of prophylactic human papillomavirus vaccines in Canada. Vaccine 25:5399-408

Centre for Reviews and Dissemination (2009) Systematic Reviews. York: CRD, University of York

Chiou CF, Hay JW, Wallace JF et al (2003) Development and validation of a grading system for the quality of cost-effectiveness studies. Med Care 41(1):32-44

Chesson HW, Ekwueme DU, Saraiya M, Markowitz LE (2008) Cost-effectiveness of human papillomavirus vaccination in the United States. Emerg Infect Dis 14:244-51

Dasbach E, Insinga R, Elbasha E (2008) The epidemiological and economic impact of a quadrivalent human papillomavirus vaccine (6/11/16/18) in the UK. BJOG 115:947-56 
Drummond M, O'Brien B, Stoddart G, Torrance G (1997) Methods for the economic evaluation of health programmes. Second edition. New York: Oxford University Press

Drummond M, Sculpher M (2005) Common Methodological Flaws in Economic Evaluations. Med Care 43(suppl 7):5-14

Drummond MF, Jefferson TO (1996) Guidelines for authors and peer reviewers of economic submissions to the BMJ. BMJ 313:275-83

Elbasha EH, Dasbach EJ, Insinga RP (2007) Model for assessing human papillomavirus vaccination strategies. Emerg Infect Dis 13:28-41

Elixhauser A, Halpern M, Schmier J, Luce BR (1998) Health care CBA and CEA from 1991 to 1996: an updated bibliography. Med Care 36:MS1-9, MS18-147

Elixhauser A, Luce BR, Taylor, WR, Reblando J (1993) Health care CBA/CEA: an update on the growth and composition of the literature. Med Care 31(Suppl 7):JS1-11, JS18-149

Gerard K, Smoker I, Seymour J (1999) Raising the quality of cost-utility analyses: lessons learnt and still to learn. Health Policy 46:219-38

Gerard K, Seymour J, Smoker I (2000) A tool to improve quality of reporting published economic analyses. Int J Technol Assess Health Care 16(1):100-10

Ginsberg GM, Fisher M, Ben-Shahar I, Bornstein J (2007) Cost-utility analysis of vaccination against HPV in Israel. Vaccine 25:6677-91 
Gonzalez-Perez JG (2002) Developing a coring system to quality assess economic evaluation. Eur J Health Econ 3:131-136

Higgins JPT, Green S (editors). Cochrane Handbook for Systematic Reviews of Interventions Version 5.0.0 [updated February 2008]. The Cochrane Collaboration, 2008. Available from www.cochrane-handbook.org

Hill SH, Mitchell A, Henry D (2000) Problems with the interpretation of pharmacoeconomic analyses. A review of submissions to the Australian Pharmaceutical Benefits Scheme. JAMA $283: 2116-21$

Insinga RP, Dasbach EJ, Allen SE, Carides GW, Myers ER (2008) Reductions in Human Papillomavirus-Disease Resource Use and Costs with Quadrivalent Human Papillomavirus (Types 6, 11, 16, and 18) Recombinant Vaccination: The FUTURE Study Economic Evaluation. Value Health 11:1022-32

Insinga RP, Dasbach EJ, Elbasha EH, Puig A, Reynales-Shigematsu LM (2007) Cost-effectiveness of quadrivalent human papillomavirus (HPV) vaccination in Mexico: a transmission dynamic model-based evaluation. Vaccine 26:128-39

Jefferson T, Demicheli V (2002) Quality of economic evaluations in health care. BMJ 324:313-314

Jit M, Choi YH, Edmunds WJ (2008) Economic evaluation of human papillomavirus vaccination in the United Kingdom. BMJ 337:a769 
Kulasingam SL, Benard S, Barnabas RV, Largeron N, Myers ER (2008) Adding a quadrivalent human papillomavirus vaccine to the UK cervical cancer screening programme: A costeffectiveness analysis. Cost Eff Resour Alloc 15:4

La Torre G, Chiaradia G, Gianfagna F, De Lauretis A, Boccia S, Ricciardi W (2006) Quality assessment in meta-analysis. Ital J Public Health 2:44-50

La Torre G, Chiaradia G, de Waure C et al (2007) Health technology assessment and vaccine: new needs and opportunities? Ital J Public Health 4:81-8

La Torre G, Chiaradia G, de Waure C, Nicolotti N, Monteduro A, Ricciardi W (2009) Report HTA del vaccino quadrivalente anti-HPV Gardasil (HTA report on quadrivalent HPV vaccine Gardasil). Ital J Public Health 6(Suppl 2):S1-S66

Mennini FS, Giorgi Rossi P, Palazzo F, Largeron N (2009) Health and economic impact associated with a quadrivalent HPV vaccine in Italy. Gynecol Oncol 112:370-6

Neumann PJ, Stone PW, Chapman RH, Sandberg EA, Bell CM (2000) The quality of reporting in published Cost-Utility Analyses, 1976-1997. Ann Intern Med 132:964-72

Petrou S, Henderson J, Roberts T, Martin MA (2000) Recent economic evaluations of antenatal screening: a systematic review and critique. J Med Screen 7:59-73

Russo P (2008) La valutazione farmacoeconomica nel contesto regolatorio italiano. Analisi qualiquantitativa dei dossier di richiesta del prezzo e della rimborsabilità. (Pharmacoeconomic evaluations in the Italian regulatory context: a quali-quantitative analysis of pricing and reimbursement dossiers). PharmacoEconomics - Italian Research Articles 10:59-75 
Siegel JE, Weinstein MC, Russell LB, Gold MR (1996) Recommendations for reporting costeffectiveness analyses. Panel on Cost-Effectiveness in Health and Medicine. JAMA 276:1339-41

Szucs TD, Largeron N, Dedes KJ, Rafia R, Bénard S (2008) Cost-effectiveness analysis of adding a quadrivalent HPV vaccine to the cervical cancer screening programme in Switzerland. Curr Med Res Opin 24:1473-83

Thurston SJ, Craig D, Wilson P, Drummond MF (2008) Increasing decision-makers' access to economic evaluations: alternative methods of communicating the information. Int $\mathrm{J}$ Technol Assess Health Care 24:151-7

Ungar WJ, Santos MT (2003) The Pediatric Quality Appraisal Questionnaire: an instrument for evaluation of the pediatric health economics literature. Value Health 6(5):584-94

Wallace JF, Weingarten SR, Chiou CF et al (2002) The limited incorporation of economic analyses in clinical practice guidelines. J Gen Intern Med 17:210-20

Weinstein MC, Stason WB (1977) Foundations of cost-effectiveness analysis for health and medical practices. N Engl J Med 296:716-21 
Figure 1. Flow-chart of the selection process

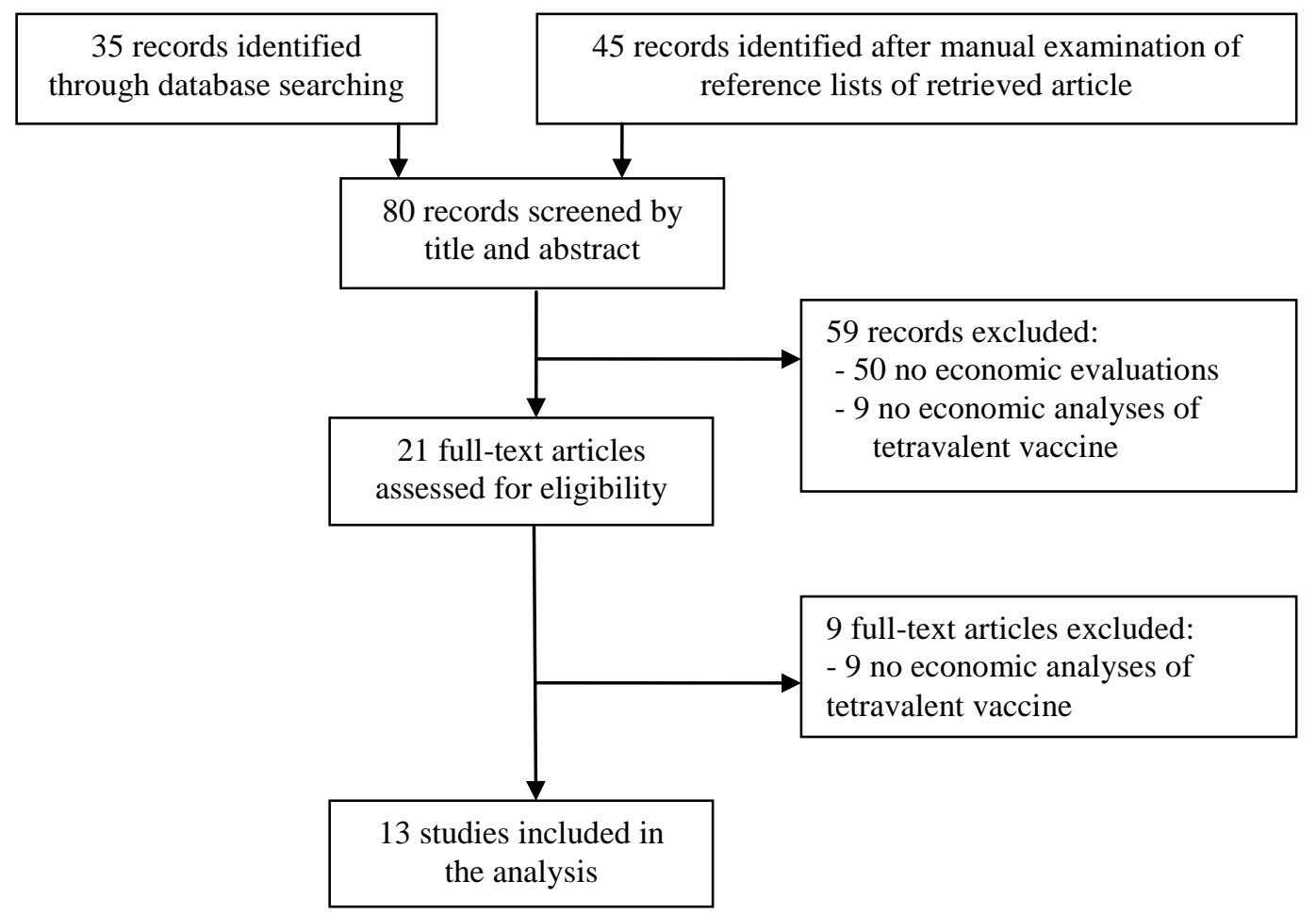

